\title{
6. Tracking Worker Deaths in Turkey
}

\author{
Pinar Dă̆
}

\begin{abstract}
Documenting worker deaths in Turkey to advocate for improved working conditions.
\end{abstract}

Keywords: Turkey, Soma, labour conditions, data journalism, open data, freedom of information (FOI)

In the wake of the Soma mine disaster in Turkey in 2014, it transpired that it was extremely difficult to document the conditions of workers. There were discrepancies with figures on worker unionization and a scarcity of data on worker deaths over previous decades. What was available was often disorganized and lacking in detail. We wanted to make this data widely accessible and shed light on the deaths of workers in other sectors.

With this in mind, a programmer, an editor and myself developed the "Open Database of Deceased Workers in Turkey," a project hosted by the data journalism portal Dă̆ Medya, that gathered data from multiple sources, verified it, and made it available for everyone to access and use. ${ }^{1}$

In Turkey at least 130 workers die per month from a variety of causes. The most important goal of the project was to raise awareness of these deaths and their frequency, as well as to publicly recognize victims and the poor working conditions that they endured. The project comprised embeddable maps, graphs and data in different formats. ${ }^{2}$ It covered the deaths of workers in over 20 sectors from 2011 to 2014. After the project was completed, we continued to report the death of workers through regular media monitoring

1 http://community.globaleditorsnetwork.org/content/open-database-deceased-workersturkey-o

2 http://platform24.org/veri-gazeteciligi/451/turkiyede-isci-olumleri-veritabani-hazirlandi (Turkish language)

Bounegru, L. and J. Gray (eds.), The Data Journalism Handbook: Towards a Critical Data Practice. Amsterdam: Amsterdam University Press, 2021 DOI 10.5117/9789462989511_CHo6 


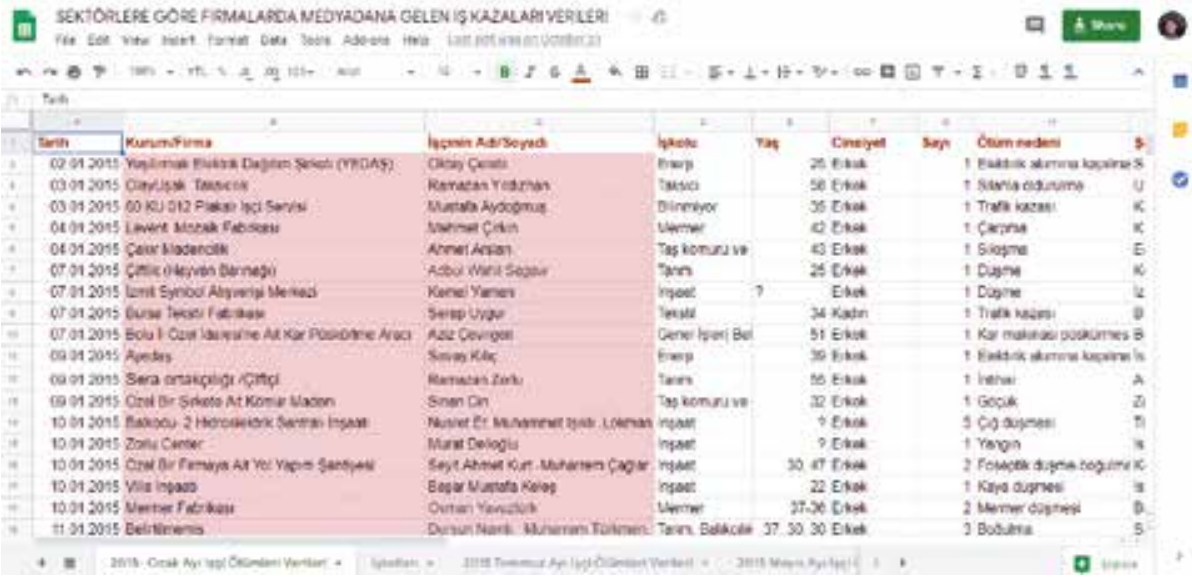

Figure 6.1. Collaborative spreadsheet with company names, based on media monitoring with Google Alerts. Source: Pınar Dağ.

each month. Crucially, the database includes the names of the companies that employed them (Figure 6.1).

The project began in 2015. We started by submitting freedom of information (FOI) requests and collecting data from trusted NGOs that were extracting data from various sources and were making it publicly accessible.

The first challenge we encountered was that it was not easy to get open data through FOI requests. Sometimes it took two weeks, sometimes four months, to obtain data through our requests. Next, a more unexpected challenge arose, which I am recounting because it surfaces conflicting perspectives on this type of work. When we announced the project, one of the projects whose data we were using-İSIG Meclisi (Health and Safety Labour Watch) - became unhappy about us using it. ${ }^{3}$ The reason was, they claimed, that our project simply republished data that they had gathered. They understood our using of their data in this way as taking advantage of their labour. The opposition to the project persisted, in spite of our asking for permission and the fact that their data is publicly available. While they accused us of "pornifying" workers' deaths with our visualizations and tables, we saw our project as creating public value by increasing the outreach of the data they had collected, through visually accessible and readily downloadable formats.

While human stories are vital, we believed that unstructured, raw data was important in order to provide a more systematic view of these injustices. We found it difficult to reach consensus around this logic and struggled to 
make the case for the value of collaborative open data-sharing practices. We ended up publishing monthly worker deaths by comparing official data gathered through FOI requests with the data that we collected through our own monitoring of these cases.

Following this project, the institutions that we petitioned with FOI requests began to share their data in a more structured way and visualize it. We took this as evidence that we had accomplished one of our goals: To make this information more widely accessible. Ultimately, the project was recognized as a finalist in the 2015 Data Journalism Awards.

\section{About the Author}

Pınar Dağ is a Lecturer in the New Media Department of Kadir Has University and the co-founder of the Data Literacy Association (DLA). 